\title{
Geflügelte Gefahren
}

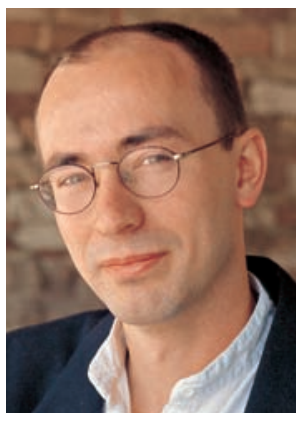

Dr. med. Dieter Schmid, Redaktionsleitung
Keine Angst! In diesem Heft geht es nicht um die Mundhygiene gefräßiger Aliens - auch wenn das unser Titelbild möglicherweise vermuten lässt. Die abgebildete Kreatur ist eine Stechmücke der Gattung Anopheles. Wenn Sie demnächst im Schwimmbad nach einem Schlummer die Augen aufschlagen, könnte es gut sein, dass dieses Tierchen auf Ihrer Nasenspitze sitzt und Sie mit seinen hübschen Facettenaugen anblinzelt. Andernorts auf der Welt überträgt Anopheles Malaria. 40 Prozent der Weltbevölkerung müssen mit der ständigen Angst vor dieser Krankheit leben. Warum Sie vor Anopheles hierzulande wenig Respekt haben müssen, dafür aber umso mehr vor anderen „geflügelten Plagen“ wie Tiger- und Sandmücken, lesen Sie in unserem Artikel „Tropenkrankheiten auf dem Vormarsch“ auf S. 36.

Die lästigen Fliegen im Studium sind die Prüfungen: Sie beschwören Versagensängste herauf und lassen chronische Nervosität keimen. Manche tragen so schwer an dieser Bürde, dass sie einen Ausweg suchen, der eigentlich keiner ist: Sie nehmen Medikamente, die ihre Ängste betäuben, und erreichen damit nur, dass ihren Sorgen erst recht Flügel wachsen. Warum Medizinstudenten pharmazeutischen Verlockungen besonders leicht erliegen, lesen Sie in unserem Artikel „Medikamentenabsus im Medizinstudium“ auf S. 14. In unserer Online-Umfrage (siehe unten) möchten wir zudem die Frage diskutieren, ob so ein „Prüfungs-Doping“ nicht zu unfairen Wettbewerbsverzerrungen führt.

Fair und gerecht ging es in unserem Zeitschriften-Wettbewerb zu. Wir suchten die beste lokale Medizinerzeitschrift. Die Redaktion der Gewinnerzeitung „Reflex“ aus Dresden hat eine Schulung mit dem Journalisten Tobias Höhn gewonnen. Einen Bericht über diese Fortbildung lesen Sie bei Via medici online (.../studienort_dresden/highlights/reflex.html). Auch wir selbst versuchen ständig, Via medici noch besser zu machen. Um allen Ihren Bedürfnissen gerecht zu werden, haben wir eine Umfrage aufgelegt. Den Fragebogen finden Sie in diesem Heft oder unter www.thieme.de/viamedici/aktuelles/aktion/umfrage2008.html. Und noch ein Tipp: Machen Sie bei unserem Fotowettbewerb „Hier lerne ich!“ mit (S. 62)! Den Teilnehmern an Umfrage und Wettbewerb winken wertvolle Preise!

Ich wünsche Ihnen ein stressarmes Restsemester. Stutzen Sie Ihren Sorgen die Flügel!

Ihr

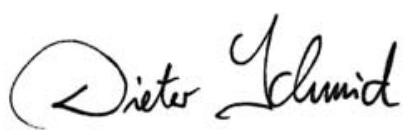

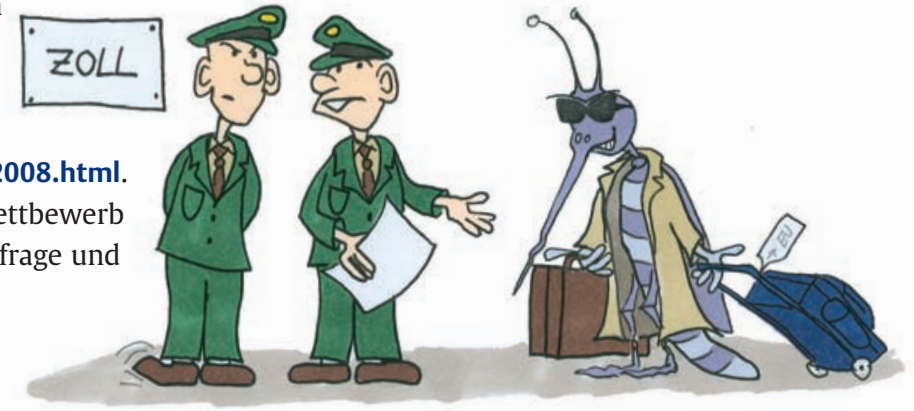

„Sie sagt, sie habe außer Dengue, Chikungunya und Kala-Azar nichts im Gepäck ... Das steht nicht auf meiner Liste. Dann muss ich sie durchlassen, oder?“

\section{ONLINE-UMFRAGE}

\section{Gedopt in die Prüfung?}

Nach einem langen Lerntag am Schreibtisch stoßen irgendwann auch die motiviertesten Studenten an ihre Grenzen. Die Lider werden schwer, der Kopf brummt. Die meisten hören dann auf ihren Körper und gehen ins Kino oder ins Bett. Andere holen sich Lernzeit und Konzentration, indem sie einen „Denkverbesserer“ wie Modafinil einwerfen. Tage später bei der Prüfung regulieren sie dann das erhöhte Erregungsniveau mit einem Benzodiazepin wieder herunter. Wie bewerten Sie so ein Verhalten? Ist das Betrug am Kommilitonen, der keine Pillen schluckt? Oder haben Sie Verständnis, wenn jemand Druck, Ängsten und Stress mit solchen Mitteln begegnet.

- Empfinden Sie es als unfair, wenn Kommilitonen Medikamente verwenden, um sich für Prüfungen fit zu machen?

Stimmen Sie ab und sagen Sie Ihre Meinung unter: www.thieme.de/viamedici/aktuelles/aktion/ miniumfrage3_08.html
Ergebnis der Umfrage in Via medici 02/08: Wir fragten, ob Sie glauben, dass eine Lerngruppe die beste Art ist, sich auf eine Prüfung vorzubereiten. $62 \%$ der Teilnehmer sahen das so und lernen gerne in Gruppen, 26\% outeten sich als Lerngruppenverächter, $9 \%$ haben eine ambivalente Einstellung. Ein Teilnehmer kommentierte: „Lerngruppen sind gut. Aber in der Zeit der Mega-Egomanen ist es schwierig, Leute zu finden, die mit einem lernen möchten. Alle sagen nur: ICH, ICH, ICH ... Da haben Lerngruppen keinen Platz." Alle Kommentare unter: .../aktuelles/aktion/miniumfrage2_08.html 